\title{
Cost Benefit Analysis
}

\section{Cost Benefit Analysis for Human} Effectiveness Research: Distributed Mission Training-

\section{Aircrew}

A Report for:

Air Force Research Laboratory

Human Effectiveness Directorate

2255 H Street, Building 248, Area B

Wright-Patterson Air Force Base, Ohio 45433-7901

By:

Michael E. Rench

Consultant

Sharon Johnson

Associate

December, 2001

Distribution Statement A: Approved for Public Release 
Public reporting burden for this collection of information is estimated to average 1 hour per response, including the time for reviewing instructions, searching existing data sources, gathering and maintaining the data needed and completing and reviewing this collection of information. Send comments regarding this burden estimate or any other aspect of this collection of information, including

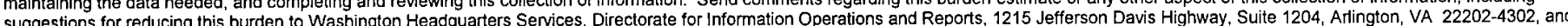
to the Office of Management and Budget. Paperwork Reduction Project (0704-0188), Washington. DC 20503

1. AGENCY USE ONLY (Leave

blank)

\section{REPORT DATE}

$12 / 04 / 01$

4. TITLE AND SUBTITLE

Cost Benefit Analysis for Human Effectiveness Research: Distributed Mission

Training-Aircrew

6. AUTHOR(S)

Michael E. Rench and Sharon Johnson

\section{PERFORMING ORGANIZATION NAME(S) AND ADDRESS(ES)}

HSIAC Program Office

AFRL/HEC/HSIAC Bldg. 196

2261 Monahan Way

WPAFB, OH 45433-7022

Commercial: (937) 255-4842 DSN: 785-4842

9. SPONSORING / MONITORING AGENCY NAME(S) AND ADDRESS(ES)

Air Force Research Laboratory

Human Effectiveness Directorate

2255 H Street, Building 248, Area B

Wright-Patterson Air Force Base, Ohio 45433-7901
3. REPORT TYPE AND DATES COVERED

Cost Benefit Analysis Report: December 2001
5. FUNDING NUMBERS

SPO700-98-D-4001

\section{SUPPLEMENTARY NOTES}

This report is one of several cost benefit efforts in the area of human effectiveness research sponsored by AFRL HE. Other specific topics include the Air Combat Capability Enhancement Suite (ACCES) and bioacoustic protection, and a state of the art report outlining the methodology needed to conduct cost benefit analyses on human centered technologies.

12a. DISTRIBUTION / AVAILABILITY STATEMENT

12b. DISTRIBUTION CODE

DISTRIBUTION STATEMENT: A

\section{ABSTRACT (Maximum 200 Words)}

Human Systems IAC was asked to perform the preliminary steps associated with assessing the costs and benefits of replacing the existing distributed mission training - aircrew (DMT-A) visual display system with the 20/20 Immersive Display System. This report details the process and results that emerged from the first three steps of an eight step process; assess current environment, perform gap analysis, and identify investment alternatives. It also outlines the remaining five steps that would need to be performed in order to complete a full cost benefit analysis (CBA).

Based on the information available, the DMT-A program is an effective tool for training pilots to work as a team. The gap analysis illustrates that some of the visual display resolution requirements are not being met and an upgrade may be needed. A potential upgrade to the status quo visual display system is the 20/20 Immersive Display System. The next steps to determining whether a new display system is warranted would be to assess the detailed costs and benefits associated with each display system. In addition, an evaluation of sensitivity and risk would need to be accomplished. Following that, the net value analysis of the investment alternatives would determine which was the preferred investment alternative.

\section{SUBJECT TERMS}

HSIAC Collection, cost benefit analysis, CBA, analysis of alternatives, AOA.

Human centered technology, HCT, HSIAC Collection

15. NUMBER OF PAGES

37

16. PRICE CODE

\section{LIMITATION OF ABSTRACT}

OF THIS PAGE

UNCLASSIFIED

\section{SECURITY CLASSIFICATION OF ABSTRACT UNCLASSIFIED}

ULIMITED

Standard Form 298 (Rev. 2-89)

Prescribed by ANSI Std. Z39-18

298-102 


\section{NOTICE}

This report is one of several cost benefit analysis efforts in the area of human effectiveness research sponsored by AFRL/HE. Other specific topics include the Air Combat Capability Enhancement Suite (ACCES), bioacoustic protection, and a state-of-the-art report (SOAR) that documents current practices and outlines a methodology to conduct effective cost benefit analyses on human centered technologies. 


\section{ACRONYMS}

\begin{tabular}{|c|c|}
\hline $\mathrm{ACC}$ & Air Combat Command \\
\hline AFRL & Air Force Research Laboratory \\
\hline AWACS & Airborne Warning and Control System \\
\hline CBA & Cost Benefit Analysis \\
\hline $\mathrm{CBR}$ & Cost Benefit Ratio \\
\hline CER & Cost Estimating Relationship \\
\hline CES & Cost Element Structure \\
\hline COTS & Commercial Off-The-Shelf \\
\hline DMT & Distributed Mission Training \\
\hline DMT-A & Distributed Mission Training-Aircrew Program \\
\hline DTIC & Defense Technical Information Center \\
\hline FOV & Field of View \\
\hline GOTS & Government-Off-The-Shelf \\
\hline $\mathrm{HE}$ & Human Effectiveness \\
\hline HSIAC & Human Systems Information Analysis Center \\
\hline IAC & Information Analysis Center \\
\hline JSTARS & Joint Strategic Tactical Air Radar System \\
\hline JTF & Joint Tactical Force \\
\hline KPP & Key Performance Parameter \\
\hline $\mathrm{LCC}$ & Life Cycle Cost \\
\hline MNS & Mission Needs Statement \\
\hline MTC & Mission Training Center \\
\hline NPV & Net Present Value \\
\hline NTIS & National Technical Information Service \\
\hline OMB & Office of Management and Budget \\
\hline ORD & Operational Requirements Document \\
\hline $\mathrm{R} \& \mathrm{D}$ & Research and Development \\
\hline SME & Subject Matter Expert \\
\hline SOAR & State-of-the-Art Report \\
\hline WBS & Work Breakdown Structure \\
\hline
\end{tabular}




\section{EXECUTIVE SUMMARY}

\section{Overview}

Due to numerous constraints (e.g., airspace, cost, safety), a simulated environment is currently the most feasible venue for US Air Force fighter pilots to practice in a four versus many opponents engagement. It is also one of the few opportunities these pilots have to work as a team with E-3 airborne warning and control system (AWACS) controllers. Logistically, it is almost impossible to assemble the resources necessary to conduct these types of exercises in real life (e.g., airspace for 20+ aircraft, maintenance, etc.). The Operational Requirements Document (Hawley, 1997) outlines the requirements for a simulation that is as real as possible. As a result, improved visual displays may be necessary to further enhance the realism and thus transfer of training potential for the simulated flights.

At the request of the Air Force Research Laboratory, Human Systems Information Analysis Center (HSIAC) performed the first three steps of an established eight step process designed to assess the costs and relative benefits of selected alternatives to one technology area, the visual display system, of the distributed mission training-aircrew (DMT-A) program. Two investment alternatives were selected with respect to the visual display system. The choices were to continue using the existing display system or to upgrade to an enhanced 20/20 Immersive Visual Display System. This report will begin the process that Air Force Research Laboratory (AFRL) can use to decide which investment alternative has the greatest payoff with respect to the established goals of the DMT-A program.

\section{Study Methodology}

Assessment of Current Environment. The assessment of the current environment was a two-part process. First, Human Systems IAC performed an in-depth literature search on relevant and reasonable resources relating to distributed mission training (DMT) generally and the visual display system specifically. Second, a Human Systems IAC analyst visited the DMT facility in Mesa, Arizona to witness the existing system in use first hand. This real-life look at the capabilities and shortfalls of the current visual system provided invaluable insight into the DMT environment as it currently exists. Additional information provided by the sponsor was also used to further supplement the information gathered by Human Systems IAC.

This assessment found that the current display system is relatively effective in meeting its training mission. However, the displays have some deficiencies that could be improved upon (e.g., resolution, brightness).

Gap Analysis. The gap analysis concentrated on comparing the goals and needs of the Air Force versus the areas where those needs are and are not being met by the existing visual display system. The result was identification of three key areas that require the most work in reaching stated goals:

- Improvement of simulator and sensor image resolution.

- Inclusion of technology upgrades:

- Collimated projection screens,

- High resolution, full color laser projectors, and

- High performance, low-cost image generators.

- Reduction of display system cost. 
Identification of Investment Alternatives. The identification of investment alternatives was accomplished through the comments and suggestions of subject matter experts and the results of the in-depth research review.

Based on the information available, the human effectiveness directorate of AFRL (AFRL/HE) has two choices with respect to visual displays systems for DMT-A. AFRL/HE can either keep the current displays and supporting equipment or elect to invest in some version of the 20/20 Immersive Visual Display System.

\section{Conclusions and Recommendations}

This study provides a start to the process needed to accurately estimate the costs and benefits associated with two potential visual display alternatives. It also illustrates the process for the remaining steps to complete the entire analysis.

Based on the information available, the DMT-A program is an effective tool for training pilots to work as a team. The gap analysis illustrates that the visual display resolution requirements are not being met and the visual display system needs to be upgraded. A potential upgrade to the status quo visual display system is the 20/20 Immersive Display System. The next steps to determining whether a new display system is warranted would be to assess the costs and benefits associated with each display system. In addition, an evaluation of sensitivity and risk would need to be accomplished. Following that, the net value analysis of the investment alternatives would determine which was the preferred alternative. 


\section{TABLE OF CONTENTS}

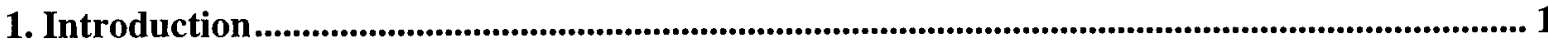

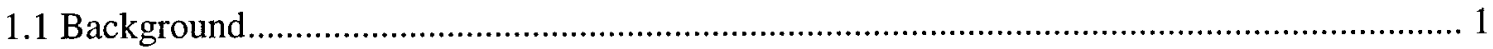

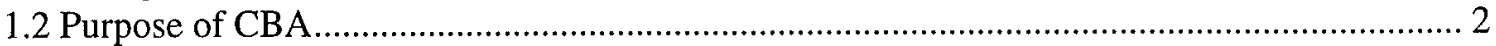

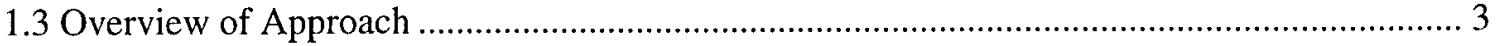

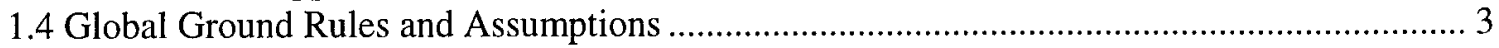

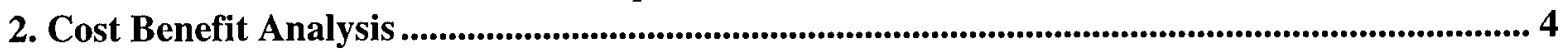

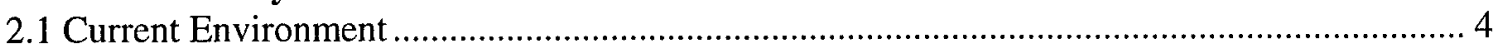

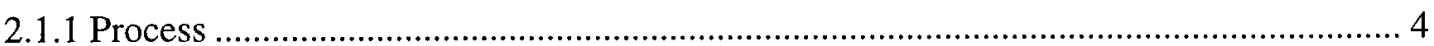

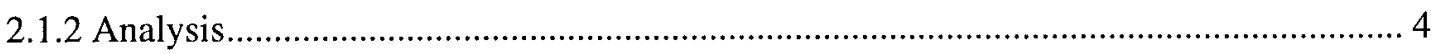

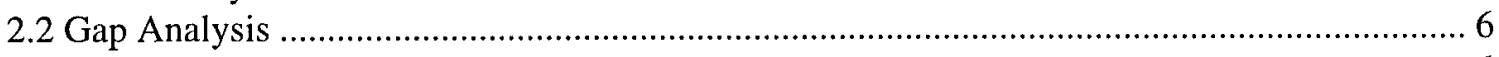

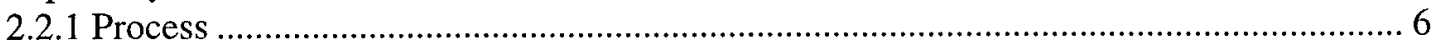

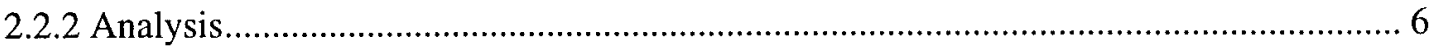

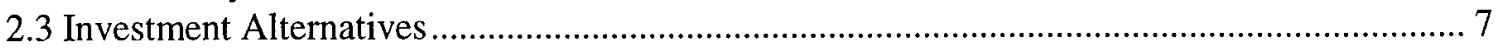

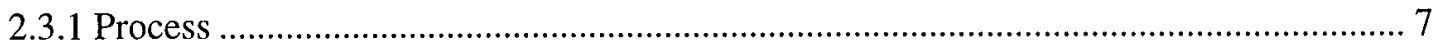

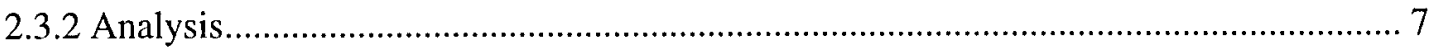

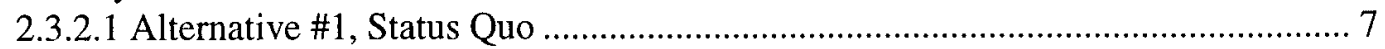

2.3.2.2 Alternative \#2, 20/20 Immersive Display System .............................................. 8

2.4 Cost Estimate

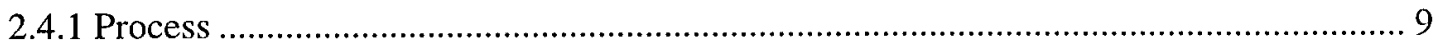

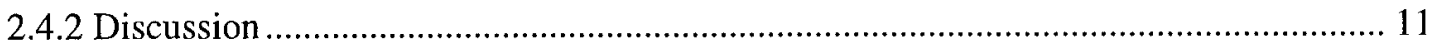

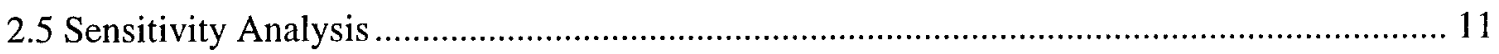

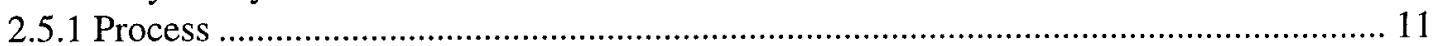

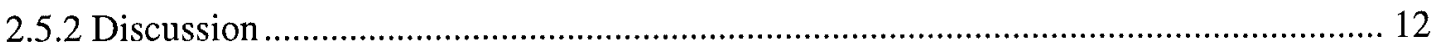

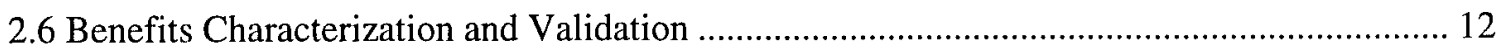

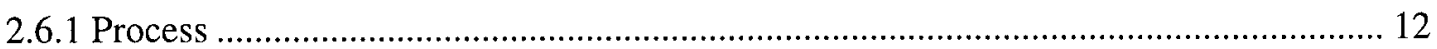

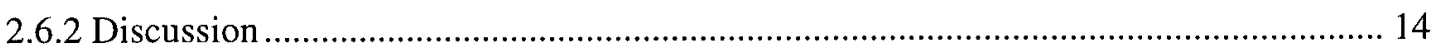

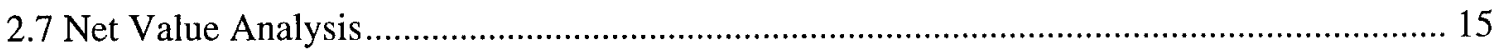

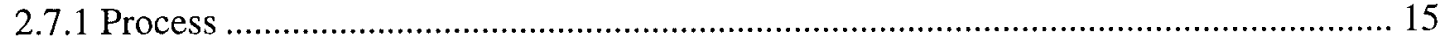

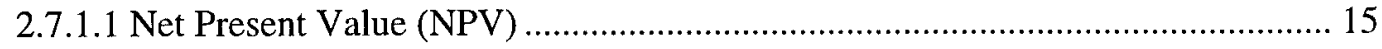

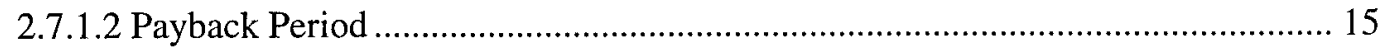

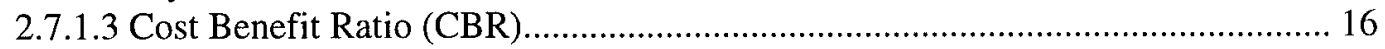

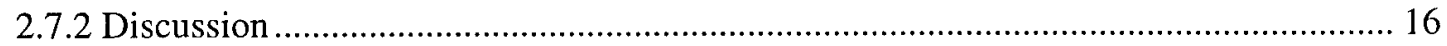

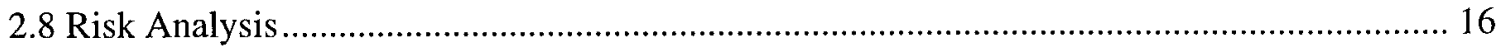

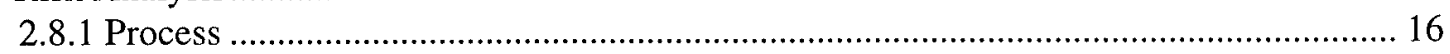

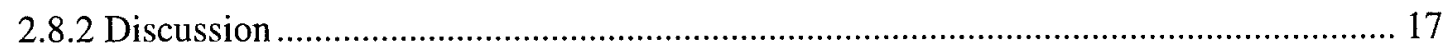

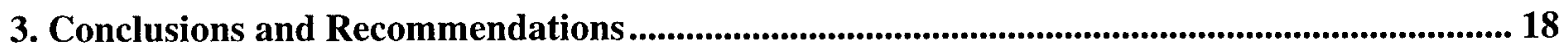

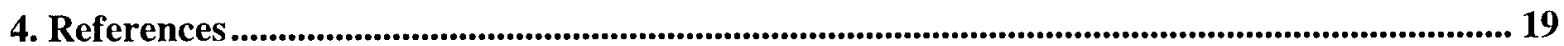




\title{
APPENDICES
}

\begin{abstract}
APPENDIX A. LITERATURE SEARCH STRATEGY …..................................................... APPENDIX B. COMMON ECONOMIC DEFINITIONS

\section{FIGURES}

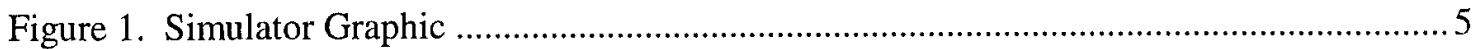

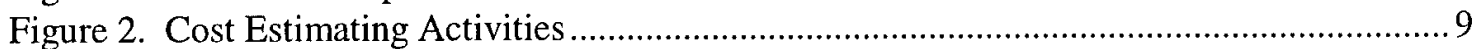

Figure 3. Relationship Between Identifying Alternatives and Characterizing Benefits ............. 13

\section{TABLES}

Table 1. DMT-A Mission Essential Competencies 2

Table 2. Comparison of Investment Alternatives 7

Table 3. Sample Generic Cost Element Structure 


\section{INTRODUCTION}

\subsection{BACKGROUND}

Success in modern aerospace warfare is dependent on the forces working well together. For this coordination to be present prior to an actual conflict, it is important for the forces to train together as they intend to fight, as an effective team (MNS, 2000). To this end, the Mission Need Statement (MNS) for the Air Force National Air and Space (Warfare) Model, identified the need to provide a training environment which integrates all Air Force missions. The training program should also be capable of training warfighters at all echelons from the Joint Tactical Force (JTF) Commander down to the individual level. According to the MNS, high-fidelity simulation, when coupled with data collection, mission replay, and performance feedback and evaluation, can improve the realism and value of training, enhance day-to-day readiness, and provide opportunities to test new tactics, techniques, and procedures (Hawley, 1999).

Prior to distributed mission training (DMT), there were several limitations present in existing training options that made it difficult to conduct effective training. From these difficulties, DMT was born. For instance, live-fly training exercises are cost prohibitive, present environmental and safety concerns, and are severely limited due to airspace restrictions. While effective at training individual skills, single-ship simulators were unable to allow operators to train as crews or as teams. Pilots for aircraft types tended to train separately, focusing only on individual skills. A final limitation to the existing training system that helped lead to the development of DMT was the limitation to sensor, communications, and navigation data. Air Force Space Command forces could not train or rehearse at full capabilities at the same time as other air or ground components. Additionally, the lack of functionality and realism in existing simulators made DMT necessary (Hawley, 1997).

"The primary purpose of DMT is to train aerospace crews and system operators in the individual, team, and composite force skills needed to accomplish their missions" (Hawley, 1998). Put simply, DMT was designed to help Air Force operators train the way they will be expected to fight. DMT was developed to fulfill the need to provide a training environment that could integrate Air Force missions at all levels of experience, from the JTF Commander down to the individual (agent) level (Hawley, 1998). Its intent was to improve the realism and value of training, enhance day-to-day readiness, and provide opportunities to test new tactics, techniques, and procedures through enhanced, high-fidelity simulation.

DMT is an Air Force readiness tool that utilizes emerging technologies to improve and integrate training and mission rehearsal. DMT is not a single project, but a federation of efforts organized into five primary domains (e.g., aircrew, mobility, special ops, space, and command and control). Each domain has its own proponents, users, and focus (Lollar, 2000). This report is in support of that portion of DMT that supports aircrew training and readiness, DMT-A.

DMT-A is an Air Combat Command (ACC) led program that focuses on the readiness needs of combat aircrews. A primary goal of the DMT-A program is to effectively train warfighters to fight as a team. The primary warfighters using DMT-A are: (Lollar, 2000).

- Pilots, weapons systems officers, and navigators of primary combat aircraft (e.g., F$15 \mathrm{C}, \mathrm{F}-16 \mathrm{C}, \mathrm{B}-1)$

- Weapons controllers and directors of combat support aircraft (e.g., AWACS, JSTARS, Rivet Joint)

- Weapons controllers assigned to Air Control Squadrons based with fighter wings 
In addition to training warfighters, DMT-A also supports seven core Air Force tasks and associated subtasks (Lollar, 2000):

- Air and Space Superiority,

- Precision Engagement,

- Information Superiority,

- Global Attack,

- Agile Combat Support,

- Global Mobility, and

- Command and Control.

DMT-A uses training and rehearsal as the sources for developing performance measures to determine success in each of the essential areas of competency for DMT-A listed in Table 1.

Table 1. DMT-A Mission Essential Competencies

\begin{tabular}{|l|l|l|}
\hline Level & Training & Rehearsal \\
\hline Individual & $\begin{array}{l}\text { Weapons employment } \\
\text { Threat reactions } \\
\text { Mission qualification } \\
\text { Fighter weapons instructor course preparation }\end{array}$ & $\begin{array}{l}\text { Theater area } \\
\text { familiarization }\end{array}$ \\
\hline Team & $\begin{array}{l}\text { Mission preparation, briefing and debriefing } \\
\text { Rapid scenario development } \\
\text { Flight leader upgrade }\end{array}$ & $\begin{array}{l}\text { Rules of engagement } \\
\text { Target area de-confliction }\end{array}$ \\
\hline Interteam & $\begin{array}{l}\text { Large force employment } \\
\text { Mission commander upgrade } \\
\text { Battle management }\end{array}$ & $\begin{array}{l}\text { Mission performance } \\
\text { analysis } \\
\text { Combat mission practice }\end{array}$ \\
\hline
\end{tabular}

(from Lollar, 2000)

The ability to train as they will fight improves the readiness of fighter and AWACS aircrew and allows for practice opportunities not available in live flight. To this end, it has been established that more realistic representation of the synthetic environment will improve transfer of training and reduce negative training while in the simulator. That is, operators can easily apply skills learned in the simulator to live-flight and that no bad habits are learned while practicing in simulation (Hawley, 1997).

The focus of this cost benefit analysis (CBA) is on the display portion of the aircrew flight simulators. Described fully in Section 2.1.2 of this report, these displays include 360 degree field of view (FOV), limited air-to-air and air-to-ground representation, and contribute to a reasonably effective and realistic training environment.

\subsection{PURPOSE OF CBA}

In general, a CBA is a systematic method of assessing the economic desirability of selected investment alternatives based on their respective costs and benefits. The objective of the assessment is to identify one alternative that is preferable to all of the others.

The focus of this CBA is to evaluate the economic desirability of two potential DMT-A display systems. The alternative eventually implemented should result in an improvement in simulated visual and sensor image resolution. It should consist of low-cost image generators, laser projectors, and projection screens. In addition, an overall reduction in the cost of the display system is desired. 


\subsection{OVERVIEW OF APPROACH}

As stated above, a CBA is a systematic method employed to make rational decisions between alternative systems by comparing their estimated costs and evaluated benefits. Conducting a CBA assists in the allocation of limited resources by probing each investment alternative so that all questions relevant to an appropriate decision are answered. In a complete CBA, the overall objective and alternatives are clearly defined; costs and benefits are fully presented; and important assumptions, factors and judgments are highlighted. Outlined in the following sections, there are eight steps used by Human Systems IAC in conducting a CBA.

1. Assess Current Environment,

2. Perform Gap Analysis,

3. Identify Investment Alternatives,

4. Estimate Cost,

5. Perform Sensitivity Analysis,

6. Characterize and Value Benefits,

7. Determine Net Value of Each Alternative, and

8. Perform Risk Analysis.

Due to resource limitations and specified customer needs, this CBA will focus on a single technology (visual display system) within the larger gamut of the entire DMT-A program and perform the first three steps of the eight step process. The report also sets the stage for conducting a complete $\mathrm{CBA}$ on that system by outlining the remaining five necessary steps to complete the analysis on the selected system.

\subsection{GLOBAL GROUND RULES AND ASSUMPTIONS}

The following ground rules and assumptions were used in developing a plan to perform a CBA on DMT-A visual display systems:

- Two DMT-A visual display investment alternatives will be identified.

- Three of the eight CBA steps will be completed and documented.

- The process for the last five CBA steps will be provided.

- Alternatives will be compared to the target goals established in the gap analysis.

- Technology or programs peripheral to the agreed-upon visual display system will not be addressed. 


\section{COST BENEFIT ANALYSIS}

\subsection{CURRENT ENVIRONMENT}

\subsubsection{Process}

In evaluating the current environment, Human Systems IAC investigated the types of technologies currently in use. Once familiar with the overall system, the need for a material solution based on the objectives was considered.

The current technology in distributed aircrew training was surveyed and thoroughly examined to establish a baseline for the analysis. At the same time, the scope of the system was established through collaboration between Human Systems IAC and the sponsor. That is, the lines between what would and would not be included in the CBA were drawn. For example, with DMT-A, connectivity between various simulators is a significant issue. While the ability to communicate with other systems is an important aspect of DMT-A, it does not influence the display systems and will not be included within the scope of this study.

In order to properly assess the current environment, Human Systems IAC analysts first "got smart" on the topic at hand. This began with an in-house literature search to ascertain the general nature of the topic. Based on this search, a comprehensive list of keywords, catch phrases, subject matter experts (SMEs), and example articles was compiled. This list was refined and combined with a short background description of the topic, the problem, and the expected outcome. As is often the case, the customer is a SME in the field and knows a great deal about the specific topic of visual display training systems. Therefore, this search strategy was developed in close coordination with the customer in the form of review and feedback. Once coordination was received, the search strategy was provided to a Human Systems IAC search specialist who conducted an in-depth literature review of all appropriate databases (See Appendix A for Search Strategy). In the case of DMT, the search resulted in the identification of literally hundreds of citations. These citations were surveyed for the most relevant and insightful resources. The emerging sources became the backbone literature source of information used throughout this CBA.

Once the literature search was completed, selected documents were acquired. The documented information was reviewed and summarized to provide an accurate perspective of the current system. In the case of DMT-A, it was established that the current technology provides limited visual display capability. Further results of this assessment are described in the following section.

\subsubsection{Analysis}

According to the DMT Operational Requirements Document (ORD) (Hawley, 1997), realism is essential to effective training. Therefore, a key performance parameter (KPP) in aerial combat simulators is effective visual displays. Parameter $1 \mathrm{i}$ of the ORD states, "The key to training in the synthetic simulation environment is realism. Visual realism is a key factor when trying to provide realistic training for combat employment. Failure to achieve high fidelity visual cueing will result in negative training and impact combat capability." It is clear from the program requirements that the visual display system used in DMT-A training simulators must be as realistic as possible. 
Central components of this effort are unit-level mission training centers (MTCs) located on individual Air Force bases (Hawley, 1998). MTCs are made up of four functional flight simulators (e.g., four F-16 or F-15 simulators) with an AWACS station, mission control stations, and interactive debrief capabilities. Each simulator consists of a fully-functional aircraft cockpit and an immersive 360 degree field of view display (see Figure 1). While in simulated flight, the operator experiences a very realistic representation of his/her aircraft. The mission control stations include several large displays that provide valuable information to instructors or evaluators (e.g., radar information, out-the-window visuals). The MTC is supported by a local AWACS station that allows a controller to practice his/her skills simultaneously with the fighter pilots and improve the overall teamwork needed in combat situations. This collection of capabilities allows pilots to brief, fly together, and debrief in a few hours-fall within the same facility.

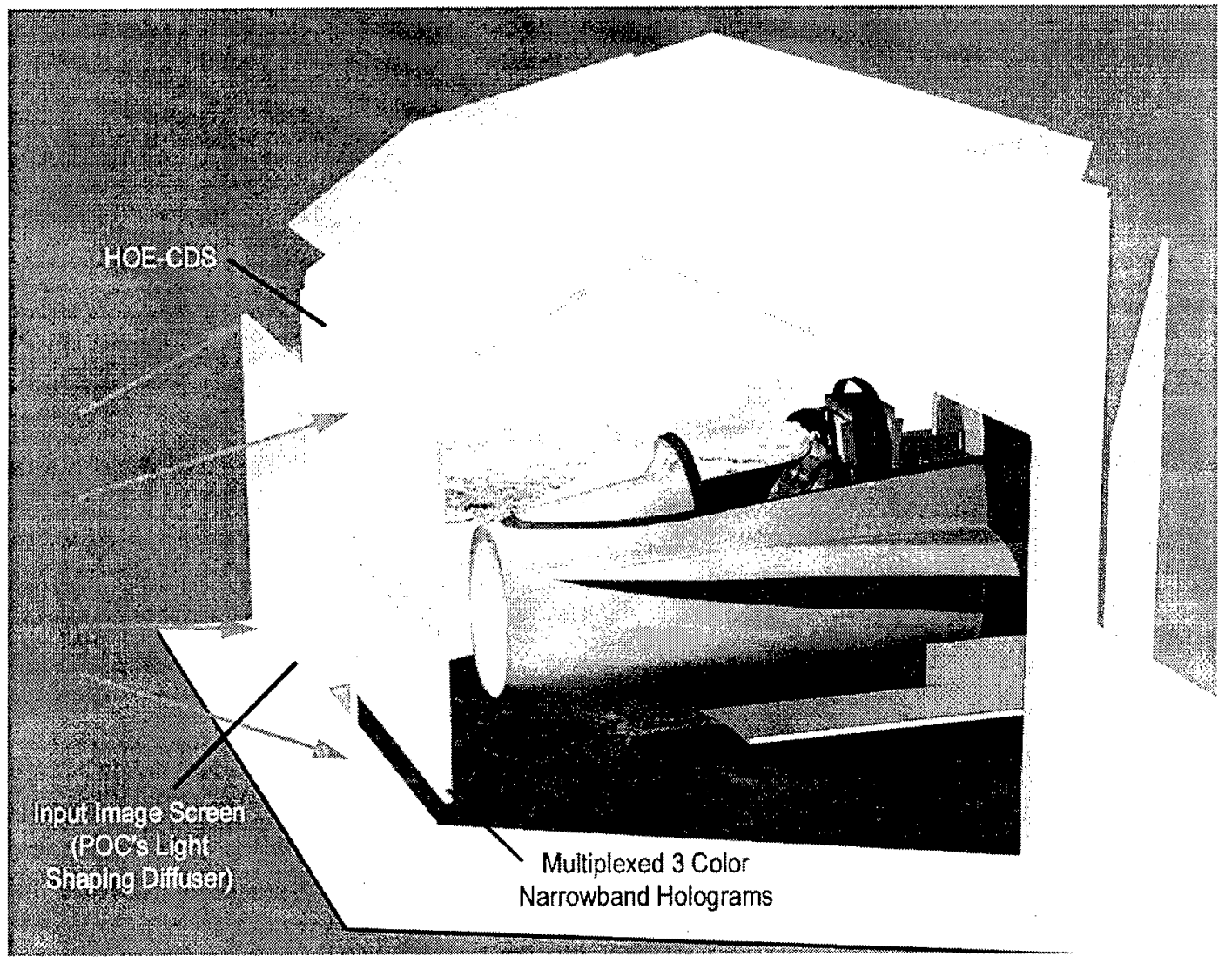

Figure 1. Simulator Graphic (from Quad-chart)

The current DMT visual display system, while effective in most aspects of simulation training, is somewhat limited in its capabilities. For example, its limited display resolution restricts the number of targets displayed at one time. The lack of resolution also inhibits the operator's perception of an object's size and distance within the visual scene. With the current display system, it is difficult for aviators to determine the type (e.g., F-16 or SU-37) and distance of another aircraft. Far off aircraft are simply "dots" on the projected display. To maintain a semblance of reality, the "dots" are color-coded depending on whether they are friend or foe (e.g., green for friend and red for foe). This color coding attempts to provide the pilots the same visual identification capabilities present in live flight. A higher resolution display system with an increased number of pixels could provide improved realism. 
Another limitation of the current display system is the brightness of the image. The current image generators simply are not bright enough to provide sharp, realistic depictions of simulated reality. Improved image generators could alleviate this problem.

A final problem with the current display system that could also be eliminated with improved imaging is ground realism. As it stands, ground images are poorly represented and unrealistic, specifically when it comes to targeting objects. Currently, computer generated ground targets stand out sharply from the basic background and make it overly easy for pilots to locate, to target, and to destroy. The outcome is that pilots are not being sufficiently challenged as they would be in live flight. This could yield negative training, which is specifically contrary to the mission of DMT-A. Improving the visual display system would eliminate this detrimental issue.

\subsection{GAP ANALYSIS}

\subsubsection{Process}

This step of the CBA investigates the gap between the current technology in use and the desired state. By understanding the requirements of the desired system and the effectiveness of the current technology (baseline) in meeting those requirements, it is determined where mission needs are not being met. In addressing the gap, it was the task of Human Systems IAC to identify critical shortfalls in DMT image generation that influence training. For example, liveflight exercises in modern fighter aircraft provide effective practice at formation flying, while they are not as effective in training against multiple adversaries. On the other hand, simulators can represent several opponents, but limitations in image generation make it impossible to practice formation flying in simulation. As a result, there is a training gap that exists in the simulator environment due to visual display limitations. Described in Section 2.1.2, certain aspects of live flight are not represented well in current DMT-A simulation (e.g., distance/size cues, ground target realism). It is this gap that should be addressed by alternative system(s). In the case of DMT-A, the investment alternative(s) are intended to reduce or eliminate the training gap so that operators can develop exceptional piloting skills without also picking up negative habits.

\subsubsection{Analysis}

Stated in the ORD (Hawley, 1997), the visual display systems for DMT-A should be as realistic as possible. This environment should include terrain, the atmosphere, and atmospheric effects. Hawley (1998) states that the visual display system should, "Allow seamless integration of live systems and events with virtual and constructive simulations and environments" (paragraph 4.3.1). The current system does not do this. As a result, an alternative system that can provide a seamless transfer of training from simulator to aircraft is needed.

The selected display alternative should result in improved simulated visual and sensor image resolution. This improved resolution, the result of an increased number of display pixels, is intended to enhance display realism and allow for better judgment of target size and distance. The alternative system should also reduce the overall cost of the display system. With new Commercial Off the Shelf (COTS) and Government Off the Shelf (GOTS) technology, it is possible to provide improved imaging at a reduced cost. The desired system should include lowcost collimated projection screens, high resolution, full color laser projectors, and high performance, low-cost image generators (Stermer, 2001). 


\subsection{INVESTMENT ALTERNATIVES}

\subsubsection{Process}

Utilizing information from the assessment of the environment and the gap analysis, Human Systems IAC then adds customer input and the opinions of technical experts to identify potential investment alternatives. That is, based on the current environment assessment and the gap analysis, the need for an alternative system to replace the status quo is established. Often, this need is the impetus for a CBA.

Alternatives can be identified in several manners. In general, the status quo (currently fielded system) is one of the alternatives examined, as it creates a baseline for comparison. Additional alternatives are often the next generation of technology identified in the research conducted. That is the case with this study. Human Systems IAC analysts, SMEs, or the customer can also identify further choices. For the DMT-A CBA, one additional alternative was identified to compare with the status quo. This alternative was the 20/20 Immersive Display System.

\subsubsection{Analysis}

\subsubsection{Alternative \#1, Status Quo}

Described fully in the current environment assessment (Section 2.1.2), this alternative is the system currently being used. It consists of 360-degree visual displays with reasonably effective, but limited display capabilities. Some of these limitations include brightness, contrast, image resolution and the apparent distance of the projected image viewed by the pilot. Table 2 describes some attributes of the two investment alternatives that could be used for comparison. As research and development proceeds and more detailed information becomes available, a direct comparison can more easily be made. This will enhance the validity of future efforts and make decisions regarding the system more reliable.

Table 2. Comparison of Investment Alternatives

\begin{tabular}{|l|l|l|}
\hline Display Attributes & Current Display System & $\begin{array}{l}\mathbf{2 0 / 2 0} \text { Immersive Display } \\
\text { System }\end{array}$ \\
\hline Field of view (FOV) & 360 degrees & 360 degrees \\
\hline Brightness & Acceptable & Improved \\
\hline Image resolution & Acceptable & Improved \\
\hline Projection screen transmissivity & Acceptable & Improved \\
\hline Contrast & Acceptable & Improved \\
\hline
\end{tabular}


Table 2. Cont'd

\begin{tabular}{|l|l|l|}
\hline Training Attributes & Current Display System & $\begin{array}{l}\text { 20/20 Immersive Display } \\
\text { System }\end{array}$ \\
\hline $\begin{array}{l}\text { Effectiveness against multiple } \\
\text { adversaries }\end{array}$ & Effective & More effective \\
\hline Formation flying & $\begin{array}{l}\text { Not enough detail at normal } \\
\text { operational distances }\end{array}$ & Comparable to live-flight \\
\hline $\begin{array}{l}\text { Target } \\
\text { acquisition/Identification - Air } \\
\text { to Air }\end{array}$ & $\begin{array}{l}\text { Not enough detail at normal } \\
\text { operational distances }\end{array}$ & $\begin{array}{l}\text { Improved resolution allows } \\
\text { normal cues to be used (e.g., } \\
\text { direction opponent is flying, } \\
\text { flight control surfaces) }\end{array}$ \\
\hline $\begin{array}{l}\text { Four versus X-number of } \\
\text { adversaries }\end{array}$ & Limited number of adversaries & $\begin{array}{l}\text { Unlimited number of } \\
\text { adversaries }\end{array}$ \\
\hline $\begin{array}{l}\text { Target } \\
\text { acquisition/Identification - Air } \\
\text { to Ground }\end{array}$ & $\begin{array}{l}\text { Overly simplified because ground is } \\
\text { displayed at different resolution } \\
\text { than target imagery }\end{array}$ & $\begin{array}{l}\text { Integrated ground images make } \\
\text { scenarios more realistic. }\end{array}$ \\
\hline
\end{tabular}

\subsubsection{Alternative \#2, 20/20 Immersive Display System}

The goal of the 20/20 Immersive Visual Display System for DMT-A is to develop, integrate, and demonstrate a high fidelity visual display system for flight simulators. This investment alternative is intended to significantly enhance the visual system for fighter simulators and meet Air Combat Command (ACC) goals for combat operations training and mission rehearsal. This will be accomplished through the development and integration of technologies that will improve the resolution of the simulated visual and sensor imagery while reducing the overall cost of the image generation and display system. The target visual display system will meet program requirements for projections screens, projectors, and image generators.

The resulting visual display system should eliminate the need for target projectors that restrict the number of high resolution targets that can be displayed. The display system should also improve the pilot's perception of an object's size and distance within the visual scene. The resulting simulator display system should provide complete capability for those missions that require visual or sensor identification of mobile ground targets within a high definition, geospecific terrain and cultural database.

These improvements will be the result of the addition of low-cost collimated projection screens with high transmissivity, and high resolution, full color laser projectors. These projectors would display over 10 times the number of pixels currently displayed by existing projectors. High performance, low cost image generators based on commercial technology will provide high resolution visual and sensor imagery. Major program deliverables over the next several years include:

- High definition television laser projector,

- Large scale, collimated screen,

- $5 \mathrm{~K} \mathrm{x} \mathrm{4K}$ full color laser projector,

- High transmissivity, collimated screen,

- PC-based image generator and database software,

- System integration, and

- Demonstration, evaluation, and documentation. 


\subsection{COST ESTIMATE}

\subsubsection{Process}

Figure 2 summarizes the seven main activities Human Systems IAC uses in the fourth step of the CBA process, estimating cost. The cost of each of the alternatives being analyzed must be calculated for a determined period of time (e.g., 10-year life cycle) to enable accurate cost comparison between the alternatives.

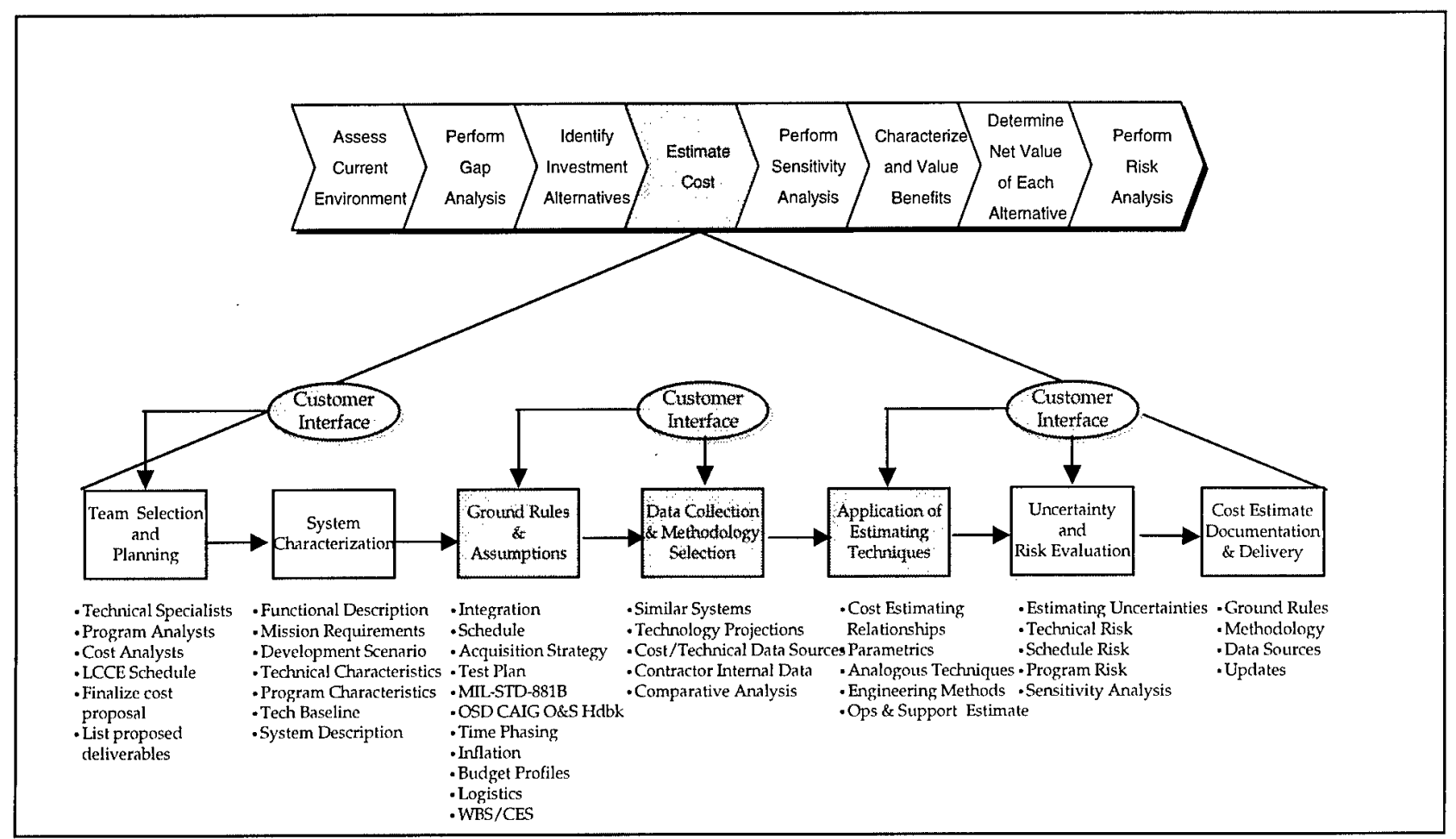

Figure 2. Cost Estimating Activities

Below each activity is a listing of items to consider and sources of information to reference when estimating costs of the alternatives. Further discussion on each activity follows.

- Team Selection and Planning: Team selection and planning activities involve identification of the program team members who will be assisting with the estimating process and the establishment of some basic information related to source selection (if applicable).

- System Characterization: This activity is very important to the success or failure of the entire estimate. During this activity, the analysts begin to gain an understanding of the item being estimated. This includes everything from basic mission requirements to the technical characteristics of the system.

- Ground Rules and Assumptions: During this activity, the cost analyst must work closely with the customer to establish key ground rules and assumptions for the estimate. This is where the estimate begins to take shape in terms of the time phasing, integration requirements and cost element structure. If one exists, the program Work Breakdown Structure (WBS) (MIL HDBK 881, 1998) should be used 
as a baseline to formulate a cost element structure (CES) for the estimate. The CES defines the cost estimate elements to be used, while providing a framework from which comparisons between the alternative solutions can be made. Table 2 below is a sample generic cost element structure.

Table 3. Sample Generic Cost Element Structure

\begin{tabular}{|l|l|l|}
\hline Development and Demonstration & \multicolumn{1}{|c|}{ Production and Deployment } & \multicolumn{1}{|c|}{$\begin{array}{c}\text { Operation and } \\
\text { Support }\end{array}$} \\
\hline Program Planning and Management & Program management & Systems Management \\
\hline Hardware & Hardware & Hardware Maintenance \\
\hline Software & Software & Software Maintenance \\
\hline Documentation & Initial Data Requirements & Site Operations \\
\hline Training & Initial Training & \\
\hline System Test and Evaluation & System Integration Test \& Evaluation & \\
\hline Logistics & Support Equipment & \\
\hline Facilities & Site Activation & \\
\hline Other & Initial Spares & \\
\hline & Industrial Facilities & \\
\hline & Warranties & \\
\hline & Initial Supplies & \\
\hline & Engineering Changes & \\
\hline & General Support & \\
\hline
\end{tabular}

- Data Collection and Methodology Selection: Once the cost element structure is established, the analyst begins to collect data. Again, the analyst must work very closely with the customer to ensure the best available information is used and all assumptions are accurate. During this activity, an initial determination is made on which cost estimating methodology will be used. Early in the program, estimates may need to be based on comparisons to similar systems (if they exist). Later in the development process, the estimate may be able to be based on known detailed design costs or the cost of previous buys of the same or similar equipment.

- Application of Estimating Techniques: Within this activity there are three commonly used cost estimating approaches.

- Analogy Approach: The analogy approach is based on direct comparison with historical information of similar existing activities, systems, or components. This technique subjectively compares the new system with one or more existing systems for which there is accurate cost and technical data. Adjustments may be made to account for complexity differences between the two systems. This method is usually quick and inexpensive, but may not be as precise, given the subjective nature of the comparison.

- Parametric Approach: The parametric approach is based on costing physical attributes or performance characteristics and their relationships to highly aggregated component costs. Cost estimating relationships (CER) are used to predict the cost of an item or effort as a function of one or more independent or explanatory variables (e.g., physical characteristics). This method can easily accommodate changes in design, performance and programmatic characteristics (e.g., "what-if" drills), but the precision of this approach is only as good as the source database. 
- Engineering Approach: The engineering approach is a "bottoms-up" method that requires the analyst to have an extensive knowledge of the system characteristics. This enables him/her to construct a detailed build up of estimates, usually by specific task (e.g., labor hours x labor rates, material cost). Frequently, actual costs available to this level of detail are used as a basis to determine first unit costs that can then be used in the application of learning curve theory. This method of cost estimating is the most detailed of all techniques and the most time consuming.

- Uncertainty and Risk Evaluation: During this activity, the analyst reviews all cost elements for potential technical, schedule, and program risk. Normally, the largest cost drivers are carefully examined and a sensitivity analysis is performed. See sections 2.5 and 2.8 for a further discussion of sensitivity and risk analyses as they relate to the overall CBA process.

- Cost Estimate Documentation: The final activity of any cost estimate is to ensure the documentation to support the estimate is in order. At a minimum, it should clearly outline the ground rules and assumptions, the methodology employed, and the data sources used.

\subsubsection{Discussion}

When conducting a cost analysis for DMT-A, the main hardware components of the 20/20 Immersive Display system are already known, so these elements would serve as the starting point for development of the Cost Element Structure. Items such as the high definition laser projector, collimated screen and PC-based image generator would all be separate hardware elements in the estimate. By working closely with the technical experts and the users of this proposed system, the cost analyst will gain a better understanding of the system requirements and should therefore be able to determine which methodology to employ to obtain the most accurate cost estimate.

\subsection{SENSITIVITY ANALYSIS}

\subsubsection{Process}

The sensitivity analysis illustrates how changes in key assumptions and variables may have an impact on the total cost estimate. These changes are often referred to as "excursions." They answer the question, "What elements, if changed, would influence the overall cost of each alternative?" The result of such an excursion assesses the magnitude of change required within key cost elements sufficient to influence the outcome of the cost analysis. While many different excursions could be evaluated, the ones most likely to be of interest to the reviewers of the analysis are selected.

Even though every effort is made to ensure the accuracy of cost estimates, the very nature of forecasting into the future presents a certain amount of risk and uncertainty. As long as the risk is identified, it can be managed and controlled. To account for the uncertainty and the lack of precision in each of the assumptions, input variable distributions (minimum, most likely, maximum) can be estimated for key cost elements. Once the cost estimate model is completed for each alternative with the input variable distributions, the model can then be subjected to a Monte Carlo simulation.

A Monte Carlo simulation calculates numerous scenarios of a model by repeatedly picking random values from the input variable distributions for each "uncertain" variable and calculating the results. The results of Monte Carlo simulations are risk-adjusted estimates and 
corresponding statistical estimate distributions. The estimate distributions provide the decisionmaker with a range of possible outcomes and bounds, with a minimum and maximum value. The input variable distributions and cost estimate range is provided with each alternative analysis.

While sensitivity analyses can occur at any stage of a CBA, it generally makes sense to derive an unconstrained material solution that meets all mission objectives initially, and then begin to "back off" that solution in the interests of saving money. Care must be taken, however, not to impact the material solution to such an extent that the benefits derived from that solution are significantly altered through introduction of the changes.

\subsubsection{Discussion}

When conducting a sensitivity analysis on the visual display system for the DMT-A program, it will be important to select excursions that will have a significant impact on the costs of the system. For instance, the more complex the technologies that will be inserted, the more likely it will be that budget and time constraints will be sensitive to change. This could be due to the reliability of components or the stability of the software to be used. Delays resulting from unreliable components could shift schedules and cause unforeseen and unbudgeted delays. Thus, these are areas that will likely be considered. Additional areas of concern may be the reliability of cost data or the type of benefit information available for analysis. However, it is necessary to carefully examine the actual cost elements to determine where further analysis needs to occur.

\subsection{BENEFITS CHARACTERIZATION AND VALIDATION}

\subsubsection{Process}

In addition to the costs, a CBA identifies and analyzes the benefits of each of the investment alternatives. In many respects, this step is a logical continuation of Step 3, identification of investment alternatives. Figure 3 illustrates the relationship between the process used to define investment alternatives and the process for identifying benefits associated with those alternatives. The key to this relationship is a thorough understanding and documentation of the mission requirements, which includes goals and objectives of the acquisition. Ultimately, the CBA is attempting to identify how to measure the attainment of the goals and objectives, and then "score" each alternative on the extent to which it satisfies those goals and objectives. 
-Identify Functional Requirement -MNS/ORD

-Mission Area Roadmap

-Define Goals and Objectives

- Key Performance Parameters

-Acknowledge Tolerable levels of risk

-Define Material Solutions

-Investigate current Inventory of Systems and Technologies

-Investigate feasibility of using particular designs/technologies

-Decompose goals and objectives down to lowest level

-A lowest level goal/objective is specifically measurable

-Include ALL lowest level goals/objectives

-Define Criteria for scoring alternatives

\section{Characterize Benefits}

Figure 3. Relationship Between Identifying Alternatives and Characterizing Benefits

It is important that all significant benefits, whether quantifiable or nonquantifiable, be included in the analysis. Quantifiable benefits are those that can be measured or assigned a numeric value, such as dollars, physical count of tangible items, time, revenue, or percentage change. Dollar valued benefits comprise cost reductions, cost avoidance, and productivity improvements. Nonquantifiable benefits include enhanced information security, consistency and compatibility throughout the enterprise, improved quality, enhancement of best practices, adherence to statutory and regulatory requirements, and enhanced modernization.

The process of identifying and quantifying benefits is often the most difficult part of conducting the CBA. It is important to follow a disciplined approach to defining benefits to ensure all relevant benefits are considered. The following is a proposed 4-step process that can be used to benefit identification (Defense Financial Management Reference Guide, 2000):

- Identify the types of resources flowing into the system and identify the resulting benefits flowing out.

- Anticipate what is important (both positively and negatively) from the viewpoint of each person affected by the system (stakeholders).

- Define each benefit in relation to the alternatives. All benefits included must be relevant, clearly and distinctly identifiable, and should not overlap any other measure.

- List the benefits of each alternative, both quantifiable and nonquantifiable. 
Typically, some benefits may be characterized in financial terms, while other benefits may not. Financial benefits provide the most efficient means of determining the net value of the investment alternative as they provide a net gain or loss of dollars based on the impact of the benefit.

Benefits gained from the use of human-centered technologies generally fall into the category of nonquantifiable benefits. For example, improvements in the reality of a visual display is a benefit, but difficult to quantify. While difficult to assess, it is important to develop some system of measurement to allow direct comparison of alternatives for each benefit. Several automated tools exist for benefits evaluation. Automated evaluation tools attempt to minimize the guesswork in decision-making. The underlying framework is an analytical hierarchical process used to organize the thoughts and intuition of key stakeholders in a logical fashion. This hierarchic approach allows the decision maker to analyze all options for more efficient decisionmaking. One such decision support software tool that is widely used in both industry and Government evaluations is Expert Choice.

\subsubsection{Discussion}

When conducting a benefits analysis for DMT-A, it will be important to address both the quantitative and nonquantitative benefits. Some potential quantitative benefits that may influence the net value would be cost savings related to sustainability and measurable display improvements. Some potential nonquantitative benefits are listed below.

- Compatibility - Will current or new display system be compatible with existing and future upgrades of DMT-A technology?

- Functionality - Will display system operate at same or increased rate? Will display system exhibit new or improved functions if upgraded?

- Maintainability - Will changes in system influence the ease and efficiency of visual display maintenance?

- Mission effectiveness - Will changes in the display system have an influence on mission effectiveness? Will a more realistic image result in more bombs on target?

- Morale - Will changes in visual display system have an influence on user morale?

- Safety - Will changes in the visual display system influence safety in live flight? Will lessons learned in simulation result in fewer casualties?

- Situational awareness - Will changes in the display system have an influence on operator situational awareness?

- Teamwork - Will changes in the visual display system have an influence on operators' ability to work as a team?

- Usability - Will changes in the visual display influence the ease of operator use?

Once all quantitative and nonquantitative benefits are identified, a total benefits rating for each investment alternative can be developed. A useful tool for this is Expert Choice. With Expert Choice, key stakeholders (e.g., engineers, pilots, program managers) are gathered and asked to form judgments about the benefits of each alternative based on information available. The result is a global benefits score that can be used to determine the net value of each alternative. 


\subsection{NET VALUE ANALYSIS}

\subsubsection{Process}

The net value analysis is process of combining life cycle costs developed in Step 4 with the benefits evaluation conducted in Step 6. The alternative with the greatest benefit-to-cost ratio is, by definition, the most cost effective. However, in some cases, the most cost-effective alternative may not be the best solution. All aspects of the alternatives must be considered, compared to one another, and an informed decision must be made.

There are a variety of statistical methods currently in use for determining the "net value" of alternatives. Most financial and project managers are using one of the following three:

- Net Present Value (NPV),

- Payback Period, or

- Cost Benefit Ratio (CBR).

The following sections examine these valuation methods in more detail.

\subsubsection{Net Present Value (NPV)}

Most corporate finance textbooks recommend net present value (NPV) as the preferred criterion for making choices among investment alternatives. In general terms, NPV is defined as the difference between the present value of benefits and the present value of costs (OMB Circular A-94). All costs and benefits are adjusted to "present value" by using discount factors to account for the time value of money. Mathematically, this definition is as shown below:

$$
\text { NPV }=\text { PV(Total Benefits })- \text { PV(Total Cost })
$$

One drawback with this method is that all benefits associated with an alternative must be able to be quantified in cost or financial terms in order to be included in the above equation. This is often not possible, especially when examining benefits in the area of human centered technology integration (e.g., impact on morale, increased productivity, decreased safety incidents).

\subsubsection{Payback Period}

Computing the amount of time it takes for a project to pay for itself (or return its initial investment) is another commonly used method for selecting among alternative courses of action. Typically, the relevant time period is expressed in terms of the number of years it takes before an investment breaks even. When using this technique, discounted cash flows are not used. In the simplest of cases, the benefits (or returns) begin predictably at the completion of the investment phase and occur in an equal amount each time period. In reality however, benefits begin accruing prior to completion of the investment phase and do not occur in equal annual amounts. In both simple and complex situations, the payback period in years, $x$, can be found in accordance with the following formula (where $t=$ time periods in years): 


$$
\sum_{t=1}^{t=x} \text { (Operational Savings }+ \text { Mission Savings) }=\text { (Initial Investment) }
$$

As with the net present value method, this method requires all benefits considered to be expressed in financial terms in order to be included in the equation.

\subsubsection{Cost Benefit Ratio (CBR)}

Another often-used method is Cost Benefit Ratio(CBR). Computation of this metric is simple:

\section{$\underline{\text { Benefits }}$ \\ Cost}

This method provides the flexibility for benefits to be assigned a "value" and therefore be considered without assigning them a price tag. Worth noting is that this seeming simplicity can be deceptive due to the fact that neither the composition of the numerator or the denominator has been universally defined or accepted. Section 2.6 provides a suggested method for evaluating non-quantifiable benefits. In addition, in order for this ratio to work, one must accurately consider in all investment alternatives, costs associated with maintaining status quo system(s) until the preferred alternative is fully fielded and any overlapping "systems" are abandoned or "turned off". The trick to making this ratio work is the development of life cycle cost estimates (LCCEs) for the Status Quo and any alternatives to it that fully represent the systems-related costs of supporting a functional mission. Presuming this has been done, then a meaningful CBR can be computed.

\subsubsection{Discussion}

When conducting a net value analysis for DMT-A, the choice of valuation method will be key. The valuation method used in any net value analysis is heavily dependent on the program manager's priorities. For example, if the analysis is being conducted to determine the most expedient solution, then payback period will be the preferred method of valuation. If the motivation is determining which solution provides the greatest amount of benefit for the funds invested, then CBR is the most appropriate method. The bottom line is that there are several acceptable methods of calculating the net value of competing alternatives. Selecting the right one for DMT-A will require additional information and consideration by the sponsor to make a recommendation.

\subsection{RISK ANALYSIS}

\subsubsection{Process}

In the final step of a cost benefit analysis, both costs and benefits are investigated from a risk perspective. The objective of this step is to isolate areas of the alternatives where uncertainties exist in the analyses. Once completed, program managers then possess the added foresight to focus their attention on those risky areas when making programmatic decisions. In general, the more complex the alternative, the more likely it is that changes in schedule/cost, or benefit assumptions will result. For example, if certain cost assumptions or benefit assessments change dramatically, the overall findings will likely change as well. 
There are various ways to categorize risks that affect investment alternatives. Provided below are definitions for five types of risk. Each program must separately determine the categories of risk to evaluate.

- Technical Risk: Technical risk is defined as uncertainty in the system performance or "benefits." Technical risk may result from an immature technology, use of a lower-reliability component, degree to which products employ the latest standards in technology and design, availability of skilled resources to support the product, and then degree of tailoring required. Technical risk can be reflected in increased costs (to fix the technical problem) and lower overall system benefits.

- Integration Complexity Risk: This category includes risks associated with the number of data dependencies, the number of actual interfaces between this module and other modules, and the technical issues involved regarding programming and application solutions.

- Market Risk: This category includes risks associated with the stability of vendors and their software and related tools and services within the market (in this case federal HR commercial off-the-shelf [COTS] product market). Market risk may increase or decrease depending on such factors as the number of vendors or products within the market, the degree to which specific products are tested and implemented in a production environment similar to the intended use of the weapons system under consideration, and implementation.

- Cost Risk: Cost risk is defined as uncertainty resulting from the use of a particular cost estimating methodology. As discussed in Section 2.4, each cost estimating methodology brings with it different strengths and weaknesses. It is during the risk analysis that these strengths and weaknesses are examined further for impact to the overall program.

- Implementation/Project Risk: This category includes risks that the module implementation will be successful and run according to planned schedule. Schedule risk is defined as uncertainty in the project completion or fielding schedule, and the subsequent impact on costs and level of benefits. A stretched-out schedule may increase costs due to extended level-of-effort funding requirements, and result in delivery of systems too late to have the desired effect (reduced benefits). This category also addresses factors such as the thoroughness of project approach and plan, the degree to which plans incorporate risk mitigation techniques, and the impact of not meeting or adjusting the project's anticipated timeline.

\subsubsection{Discussion}

When conducting a risk analysis on the visual display system of DMT-A, several factors will need to be considered. Some important factors that will influence the uncertainties of the estimation are the technical maturity of the display products to be integrated, the ease of integrating new visual displays with existing technology, the stability of vendors, and the likelihood that implementation will take place on time and within budget. Clearly, these are areas that can only be adequately addressed once all others steps of the CBA are complete. 


\section{CONCLUSIONS AND RECOMMENDATIONS}

Human Systems IAC was asked to perform the preliminary steps associated with assessing the costs and benefits of two alternatives for the visual display system of the distributed mission training program. This report also outlines the remaining five steps that would need to be performed in order to complete a CBA.

Based on the information available, the DMT-A program is an effective tool for training pilots to work as a team. Based on the gap analysis, visual display resolution requirements are not being met completely and the visual display system may need to be upgraded. A potential upgrade to the status quo visual display system is the 20/20 Immersive Visual Display System. As additional details regarding the alternatives become available, the new information will improve the reliability of future analysis efforts. The next steps to determining whether a new display system is warranted would be to assess the costs and benefits associated with each display system. In addition, an evaluation of sensitivity and risk would need to be accomplished. Following that, the net value analysis of the investment alternatives would determine which was the preferred alternative. 


\section{REFERENCES}

20/20 Immersive Display System for DMT-Aircrew (2001) 20/20 Immersive Display System for DMT-Aircrew, Unpublished Quad-chart. AFRL/HE

Defense Financial Management Certification Program Reference Guide (2000). American Society of Military Comptrollers.

Hawley, R. E. (1998). Final Capstone Requirements Document CRD, CAF (USAF) 009-93 for distributed mission training (DMT). Headquarters, Air Combat Command.

Hawley, R. E. (1997). Operational requirements document (ORD) CRD, CAF (USAF) 009-93 IA for distributed mission training (DMT). Headquarters, Air Combat Command.

Lollar, G. (2000). The Distributed Mission Training Roadmap. Arlington, VA: DCS, Air \& Space Operations, HQ AF/XOCA.

MIL-HDBK-881 (1998). DoD Handbook - - Work Breakdown Structure. Washington, D.C.: Department of Defense.

Mission Need Statement (MNS) (1999). Final multi-command mission need statement CAF, AMC, AETC, AFSOC, AFSPC, AFRC 807-98 for distributed mission training. Headquarters, Air Combat Command.

Office of Management and Budget (OMB) Circular A-94 (1992), Guidelines and Discount Rates for Benefit-Cost Analysis of Federal Programs. Washington, D.C.: Office of Management and Budget.

Stermer, N. (2001). 20/20 Immersive display system for DMT-Aircrew. Unpublished Summary Report, March 29. Wright-Patterson AFB, OH: AFRL/HEOX. 


\section{APPENDIX A. LITERATURE SEARCH STRATEGY}

\section{Distributed Mission Training Cost Benefit Analysis}

\section{Literature Search Strategy}

For: Air Force Research Laboratory

Wright-Patterson Air Force Base, OH

\section{Background:}

Human Systems IAC is conducting the first 3 phases of the cost benefit analysis process associated with Distributed Mission Training (DMT) at a global level. These phases are 1) Assess Current Environment, 2) Perform Gap Analysis, and 3) Identify Investment Alternatives. DMT technology allows multiple players at multiple sites engage in training scenarios ranging from individual and team/battle-staff participation to full theater-level battles. Additional technologies (e.g., constructive forces) provide for nearly unlimited training opportunities for joint and combined forces. DMT dramatically improves the quality and quantity of warfighter training.

The specific goal of this literature search is to review recent literature on DMT to help Human Systems IAC identify and understand the current level of technology and research and development $(R \& D)$, specifically in government training applications. This review should also help identify the available alternatives and what the potential payoffs are for continuing R\&D in the area of DMT. This information will then be evaluated with the cost data to determine the alternative technology with the greatest return on investment.

The results of the literature search strategy will be used to derive cost and benefits as appropriate. The results are especially important in capturing the "value" of benefits in order to quantify them in our final analysis.

\section{Search Terms:}

See attached table of terms.

Key Authors:

Jesse Orlansky

Henry L. Taylor

Possible Databases: (Final list to be determined based on customer and expert searcher recommendations)

Aerospace Database

DTIC

ISI Science Citation Index

NASA Recon

NTIS

PsychINFO 


\section{Example Articles:}

Dwyer, D., Oser, R., \& Fowlkes, J. (1995). A case study of distributed training and training performance (pp. 1316-1320). In Proceedings of the Human Factors and Ergonomics Society $39^{\text {th }}$ Annual Meeting, San Diego, CA, October 9-13. Santa Monica, CA: Human Factors and Ergonomics Society.

Jackson, P. M. (1996). Design considerations for interoperability in mission training systems (pp. 193-198). In S. Sestito, P. Beckett, G. Tudor, \& R. Triggs (Eds.), SimTec Proceedings. Melbourne, Australia: SimTechT Organising Committee.

Lane, N. E. \& Alluisi, E. A. (1992). Fidelity and validity in distributed interactive simulation: Questions and answers (DTIC No. AD-A260971). Alexandria, VA: Institute for Defense Analyses.

Mudd, D., Pierce, B., Gasson, R., Greschke, D., \& Svendson, J. (1998). Canadian Forces distributed mission training feasibility study (CF-18 Multitask Trainer) (Report No. AFRL-HE-AZ-TR1998-0084-V-1). Mesa, AZ: Raytheon Training and Services.

Orlansky, J., Taylor, J. Levine, D, \& Honig, J. (1997). The cost and effectiveness of the MultiService Distributed Training Testbed (MDT2) for training close air support (Report No. IDA/HQ-96-004084). Alexandria, VA: Institute for Defense Analyses. 


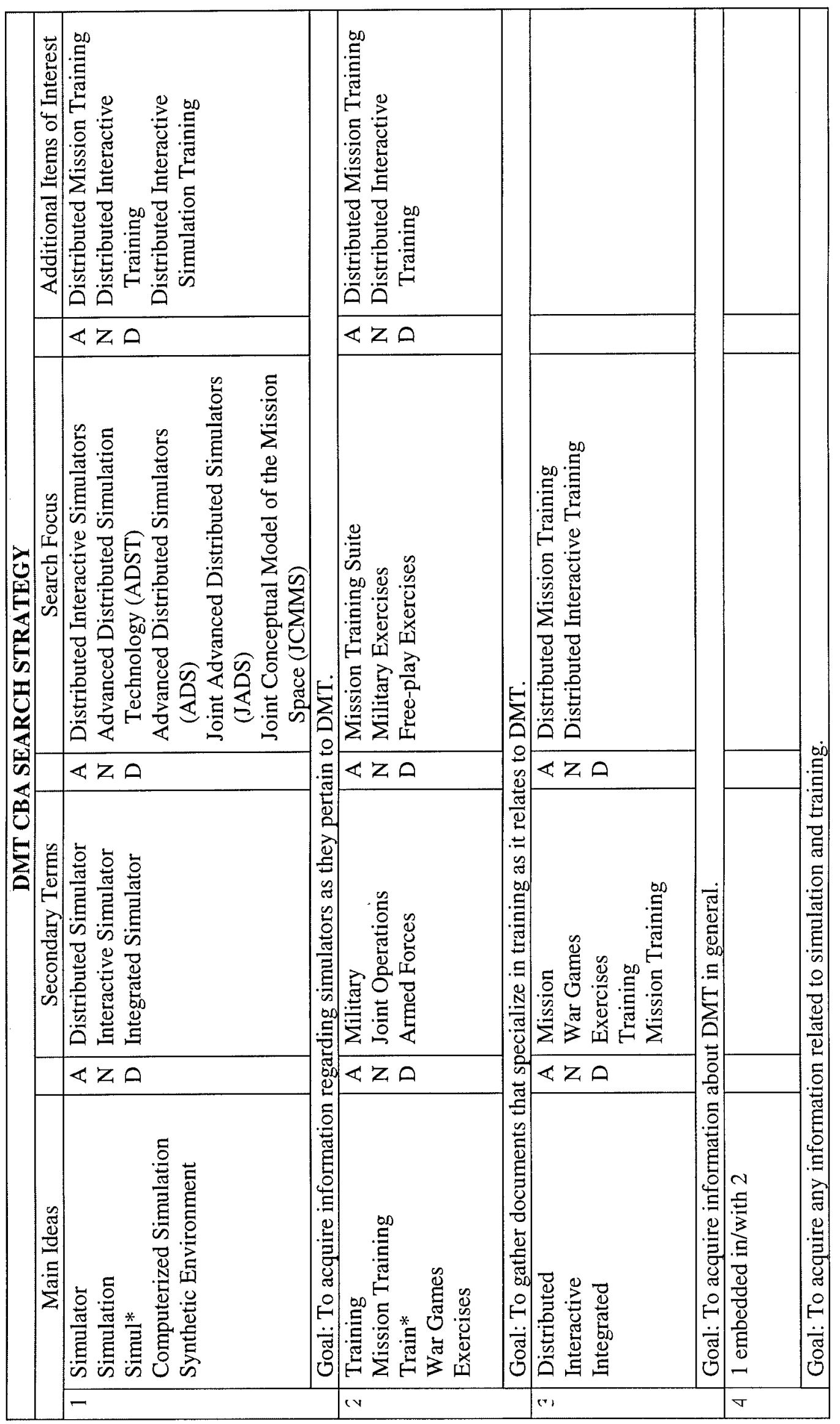

$\frac{9}{4}$ 


\section{APPENDIX B. COMMON ECONOMIC DEFINITIONS}

Alternative-An approach or program that is another possible way of fulfilling an objective, mission, or requirement. The status quo, or an upgrade to the status quo, is usually an alternative to a proposed course of action.

Analytic Hierarchy Process - The Analytic Hierarchy Process (AHP) is a powerful and flexible decision-making process used to assist in setting priorities and making the best decision when both qualitative and quantitative aspects of a decision need to be considered. AHP reduces complex decisions to a series of one-on-one comparisons, then synthesizes the results. AHP was developed more than 20 years ago by Dr. Thomas Saaty, and continues to be one of the most highly regarded and widely used decision-making theories.

Analysis of Alternatives-An Analysis of Alternatives AOA) evaluates the costs and benefits (i.e., the operational effectiveness or military utility) of alternative courses of action to meet recognized defense needs.

Base Year-A point of reference that represents a fixed price level, usually defined as the fiscal year when a program was initially funded. Expressing program costs in a specified base year is the same as expressing those costs in constant year dollars of the same year.

Base-Year Dollar-Reflects the dollar's value at the midpoint (April 1) of a given base year and implies this value throughout the base year. When cost estimates are in base-year dollars, the purchasing power of the dollar remains the same over the estimated time period.

Benefit-An objective measure of an alternative's value. When a dollar value cannot be placed on comparable program or project benefits, other objective measures may be available and useful for comparing alternatives.

Benefits Analysis-Analysis to identify, measure and evaluate the benefits for each proposed alternative.

Benefit to Cost Ratio-An alternative way to express "Cost Benefit Ratio". See Cost Benefit Ratio.

Commercial-Off-The-Shelf-Hardware or software products developed, tested, and sold by commercial companies to the general public.

Constant Year Dollar-Reflects the value or purchasing power of a dollar in any specific year, which may or may not be the base year. Constant year dollars do not contain any adjustments for inflation that has occurred or is forecasted to occur outside the base year. Constant year dollars are also not influenced by outlay profiles (expenditure patterns).

Cost Model-A compilation of cost estimating logic that aggregates cost estimating details into a total cost estimate; An ordered arrangement of data, assumptions, and equations that permits translation of physical resources or characteristics into costs. Cost models generally:

(a) Consist of a set of equations, logic, programs, and input formats to specify the problem 
(b) Allow for the input of program information, including both system description data and estimating relationships

(c) Produce an output format.

Cost and Operational Effectiveness Analysis-The COEA provides an analytical basis to support milestone decision reviews by allowing comparison of alternative solutions based on cost and performance.

Cost Benefit Analysis-A systematic approach to the problem of choosing how to use scarce resources. It reveals the monetary value of the costs and benefits associated with all alternatives under consideration, and provides as accurate and complete a picture as possible of nonmonetary costs and benefits.

Cost Benefit Ratio-The mathematical expression of the relative cost per unit of benefit obtained; lower ratios are preferred as this indicates that more benefit is gained for each dollar invested (Total Cost / Total Benefits).

Cost Element-An identifiable function, or a common group of functions, which have been established as a separate entity for the purpose of estimating, collecting, controlling, and reporting costs.

Cost Element Structure-The documented configuration of common functions which are used to systematically estimate, collect, control and report program costs.

Cost Estimating Relationship-A mathematical expression defining cost as the dependent variable to one or more independent cost driving variables.

Discount Factor-The factor that translates expected benefits or costs in any given future year into present value terms. The discount factor is equal to $1 /(1+i) t$

where $i$ is the interest rate and $t$ is the number of years from the date of initiation for the program or policy until the given future year.

Discounted Cash Flow-Periodic money stream(s) resulting from economic decisions that are adjusted for the time value of money (interest rate). Discounting cash flows allows for common comparison among competing alternatives that offer returns over different periods of time.

Economic Life-The period of time during which the benefits from a project may reasonably be expected to accrue.

Government-Off-The-Shelf-An item of hardware or software that has been produced by or for the government and is available for reuse; Products for which the government owns the data rights, that are authorized to be transferred to other DoD or U.S. Government customers, and that require no unique modifications or maintenance over the

Internal Rate of Return-The present value of the net cash flow stream expressed as an annual percentage growth rate of the initial investment (i.e. the annual compound interest rate required to produce the same result as the evaluated investment). 
Investment Analysis-The process of examining the feasibility of a particular course of action based on the costs to pursue it and resulting benefits (savings) from doing so.

Investment Costs-Those program costs required beyond the development phase to introduce into operational use a new capability; to procure initial, additional, or replacement equipment for operational forces; or to provide for major modifications of an existing capability. They exclude research, development,, test and evaluation, military personnel, and operation and maintenance appropriation costs.

Life-Cycle Cost-The total cost to the government for a system over its useful life, including the cost of development, procurement, operation, support, and disposal

Measures of Effectiveness-Operational capabilities stated in terms of engagement or battlefield outcomes. In the modeling process, they are used to assist in discriminating among competing alternatives. They show how the alternatives compare in meeting functional objectives and mission needs.

Measures of Performance-MOPs are technical data elements supporting a MOE.

Mission Life-The time period of program use or operation.

Mission Needs Statement-A requirements document that outlines a deficiency based on operational capability, rather than system specifics. The MNS identifies the need to establish a new operational capability, improve existing capabilities, or exploit an opportunity that cannot be satisfied with non-material solutions.

Net Present Value-The present value of all revenue (savings) streams less the present value of all cost (investment) streams.

Office of Management and Budget-Office that assists the President in overseeing the preparation of the Federal budget and in supervising its administration of Federal agencies. The $\mathrm{OMB}$ also oversees and coordinates the Administration's procurement, financial management, information and regulatory policies.

OMB Circulars and Bulletins-Publications used by the Executive office of the President to exercise managerial and policy direction over Federal agencies. Circulars and Bulletins generally promote government effectiveness by providing uniform guidance to agencies.

Operational Requirements Document-A document which details the users objectives and minimum acceptable requirements for operational performance of a proposed concept or system.

Present Value-Monies accruing in the future that have been discounted to account for the fact that those monies will be worth less in the future than they are today.

Recurring Costs-Expenses for personnel, material consumed in use, overhead support services, and other items incurred on a repeating basis.

Return on Investment-Net income divided by investments. 
Risk-The likelihood that some assumption or estimate is wrong. Sometimes used synonymously with "uncertainty," though uncertainty can be described by a probability distribution.

Savings to Investment Ratio-The ratio of the present value of a savings stream with respect to the present value of the cost of making the investment.

Sensitivity Analysis-Examination of the effects obtained by changing the direction and magnitude of assumptions embodied in an analysis or key variables or factors in an analysis.

Sunk Cost-The sum of past expenditures or irrevocably committed funds related to a project. Such costs are generally not relevant to decision making as they reflect previous rather than present choices.

Work Breakdown Structure-A product-oriented family tree, composed of hardware, software, services, and other work tasks, which results from project engineering effort during the development and production of a defense materiel item, and which completely defines the project or program. 


\section{About Human Systems IAC}

The Human Systems Information Analysis Center (Human Systems IAC, HSIAC) is the gateway to worldwide sources of up-to-date human factors and ergonomics information and technologies for designers, engineers, researchers, and human factors specialists. Human Systems IAC provides a variety of products and services to government, industry, and academia while promoting the use of human factors and ergonomics in the design of human-operated equipment and systems.

Human Systems IAC's primary objective is to acquire, analyze, and disseminate timely information on human factors and ergonomics. In addition to providing free basic searches, Human Systems IAC performs other services on a cost-recovery basis:

- Distribute human factors and ergonomics technologies and publications

- Perform customized bibliographic searches and literature reviews

- Prepare state-of-the-art reports and critical review

- Conduct specialized analyses and evaluations

- Organize and conduct workshops and conferences

Human Systems IAC is a Department of Defense Information Analysis Center sponsored by the Defense Technical Information Center. It is technically managed by the Air Force Research Laboratory Human Effectiveness Directorate and operated by Booz Allen \& Hamilton Inc. 
Published by:

The Human Systems Information Analysis Center HSIAC)

ARFL/HEC/HSIAC

2261 Monahan Way, Bldg. 196

Wright-Patterson AFB, OH 45433-7022

Phone: (937) 255-4842 DSN: $785-4842$

Fax: $\quad$ (937) $255-4823 \quad$ DSN: $\quad \mathbf{7 8 5 - 4 8 2 3}$

E-mail: tom.metzler@wpafb.af.mil

WWW: http://iac.dtic.mil/hsiac./
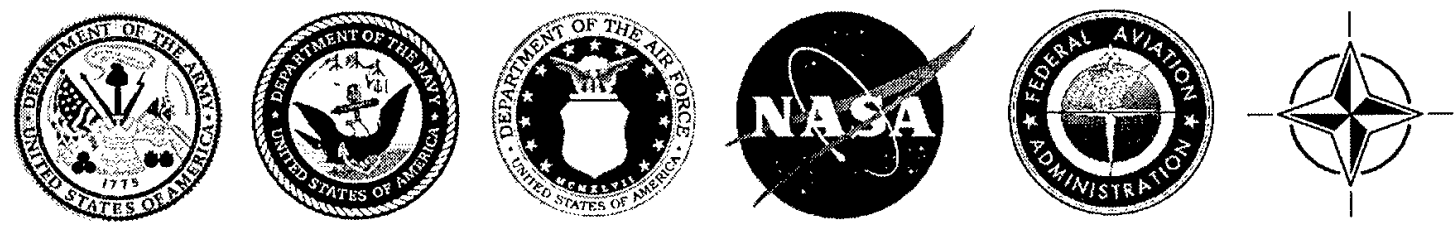
B-1 